\title{
دراسة تأثير بكتريا Streptomyces على مكونات النفط الخام
}

\author{
نزار أدور ناصر ، قسم علوم الحياة ـ كلية العلوم ـ الجامعة المستتصرية
}

\section{الخـلاصـة}

\section{المقدمــــة}

استخدمت في هذه الدر اسة عشـرة

sp.

عزلات بكتبرية من الجنس فلتس

Streptomyces

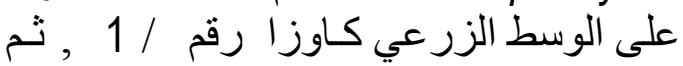

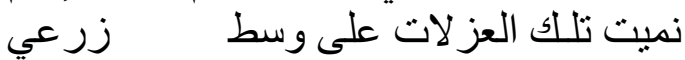

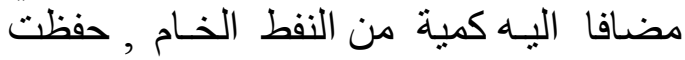
في الحاضنة الهزازة في 28 مج ولمدة 14

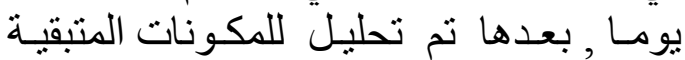

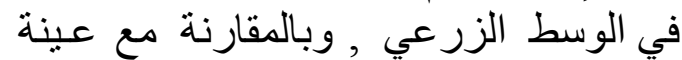
السيطرة باتباع طريقة الكروماتوكر الفي

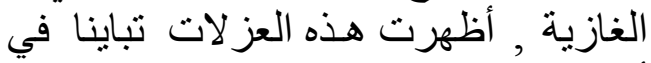

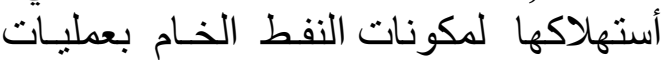

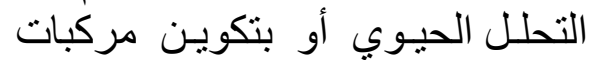

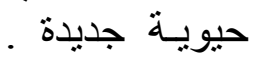

\section{ABSTRACT}

Ten bacterial isolates of the genus Streptomyces sp., were reactiva- ted using Gauza no.1 medium, and grown on crude oil medium, incubated at $28^{\circ} \mathrm{C}$ for 14 days in a shaker incubator. Analysis of the remaining crude oil contents by these isolates in comparison with control sample by $\mathrm{GC}^{*}$ , had shown differences in their ability to consume the components of crude oil as a result of biodegredation or biosythesis of new compounds.

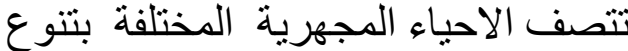
فعالياتها الحيوية وبعضهاه التحثبة التبر صفات

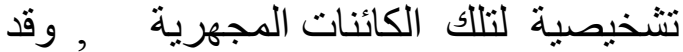
درس الانسان هذه الفعاليات وحاول النيات فئل يستفاد منها في حياته اليومية في مجال البيات اليئة

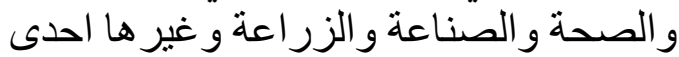
هذه الدجالات هي مشاكل التلوث البيائي

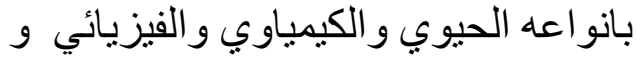
كيفية تسخير فعاليات الاحياء المجهرية في المياني

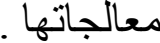

احد انواع التلوث البيئي هو التلوث بالنفط

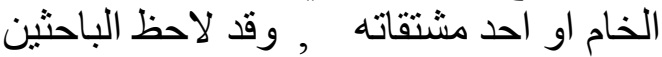

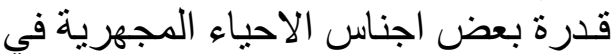
تحليل المركبات الهيدروكربونية المكونة المئة

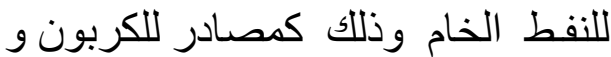

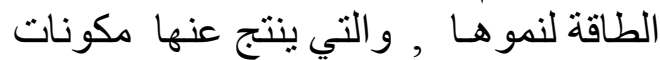
بسيطة غير مؤثرة على البيئة , اولى هذه

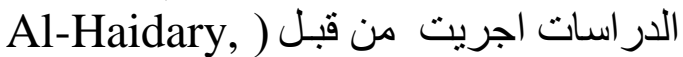

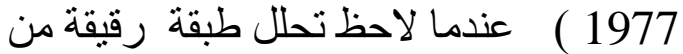
البار افين ـ بعده تو الت الدر اسات حول هذا الموضوع مثنل . Wilhelms et al 2001 ; Larter et al. 2003 ; Chaillan et al. 2004 ; Das and , حبـ Mukherjee 2007 ) وجدوا أن للاحياء المجهرية القدرة على القي لفي

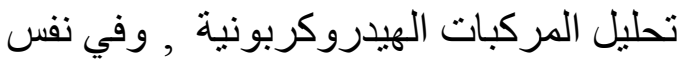

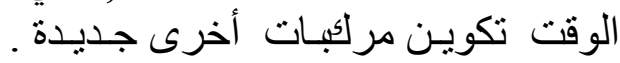
* GC : Gas Chromatography . 
المواد المستعملة وطر ائق العمـل

sp.

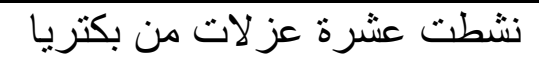

Streptomyces

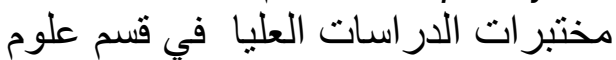

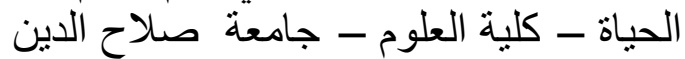
على وسط كاوزا رقم /1 وحفظت في 28 مج ولمدة اسبوعين, ثم تم تلقح الوسط Basal mineral salt agar الزرعين (ناصر 1989 ) المضاف لـه النفط الخام

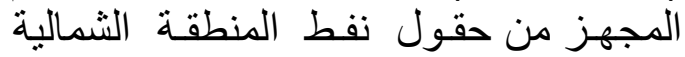

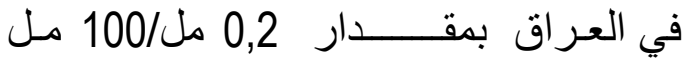

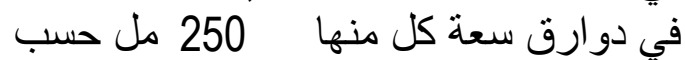
طريق (Pridham and Gottlieb, 1948)

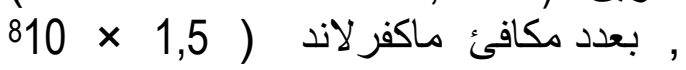
( Baron and Finegold,1994) ml/cfu( من مزارع فنتيـة للعزلات فيد الدراسة و و

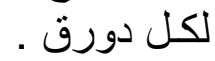
مكافئ ماكفر لاندـ القياسي يستخدم

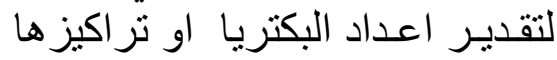
وتســـ تحضيره كمـا يأتي : محلول رقم / 1 : : باذابة ( 1 (1,175 غم ) من كلوريد الباريوم في ( 100 مل ) من

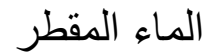

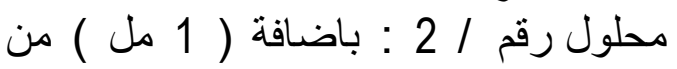
حامض الكبريتيك المركز الى ( 100 مل ) من ) من الماء المقطر . أضيف مقدار ( 0,5 مل) من محلم الملول رقم

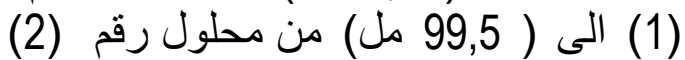
ومزج الخليط ثم حفظ في انابيب اختبار

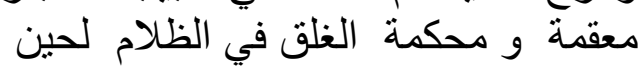
الاستخدام لمعايرة عدد خلاّيا البكتريا و الذي الذي

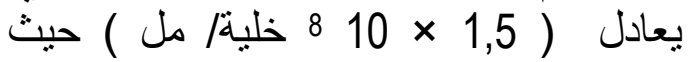
يعطي طيف امنصاص ( 0,2 نانو ميتر ) عند قياسه بجهاز المطياف الضوئي على نـى طول

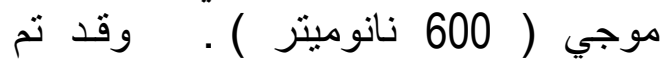

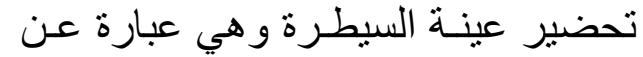

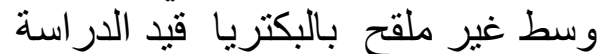

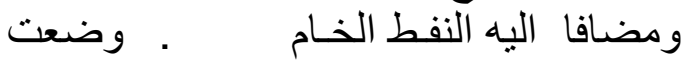

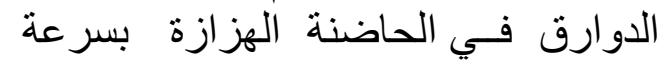
(وبدرجة حرارة 250 rpm ) ولمــدة اسبوعين.
بعدها تم مقارنة نتائج نمو العزلات من

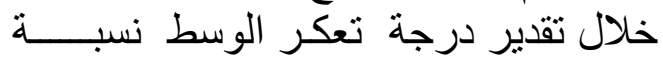

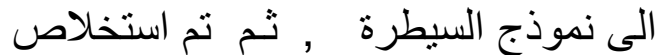
مكونات النفط الخام المتبقية في في الوسط

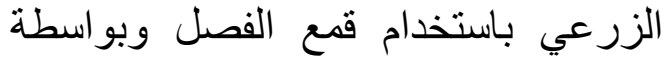
مذيب ثنائي ( بنزين- ايثانول 1 : 1 ) ثم ثم

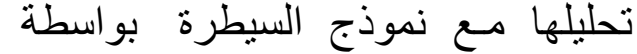

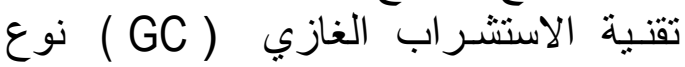
و العمود الحاوي (Shimadzu GC - 7A)

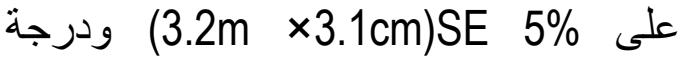
حرارة الحقن 300 مم فيما كانت درجة حرارة العمود 80 مم مبرمجة فئة في معدل

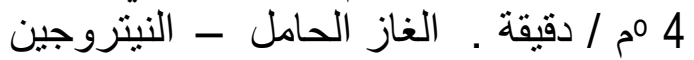

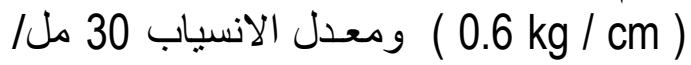
دقيقة , المكثاف FID ونوع الحاسوب ( Shimadzu - SR - 3A Chrompack )

\section{النتائـج و المناقثــة}

تباينت معدلات نمو عزلات البكتريا على الوسط الزرعي الحاوي في مكوناته

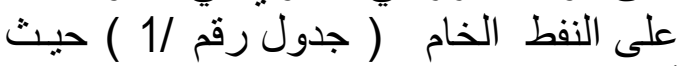
أن العزلات ( 2 و 3 و و 4 و و 9 ) ) كان نموهـا ضعيفا , تليها العزلات اتل ( 1 ( 1 و 5 و و

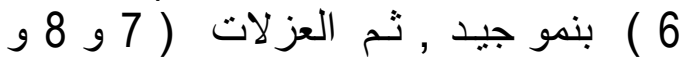

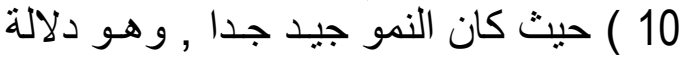
على قدرة هذه العزلات بلات باستهلاك

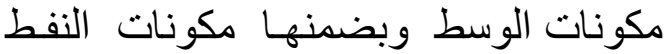
الخـام عند مقارنتهـا بعينـة السيطرة وهـو مطابـق مـع العديد من الباحثين

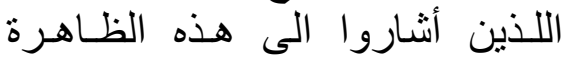
من من

Head et al., ; Larter et al. , 2005) . 2003

تم تحليلـ متبقي النفط في الوسط الزرعي

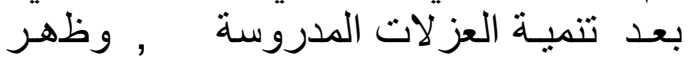

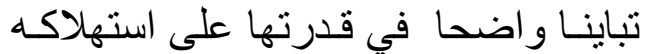

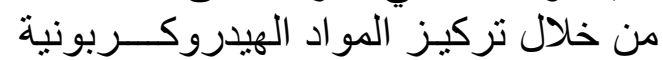

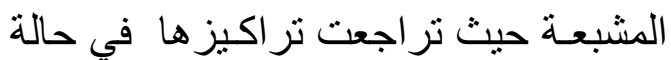
العزلات ( 1 و 5 و 6 و 7 و 8 و 10 ) في حئ في 
حين اظهرت العزلات ( 2 و 3 و 4 و و 9 )

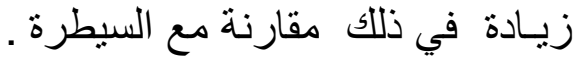

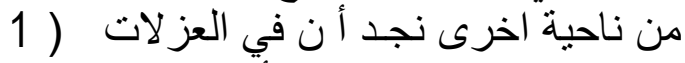

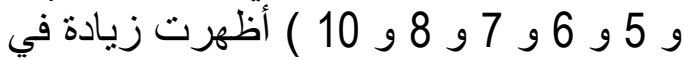
نسبة تركيز الهيدروكربونات الاروماتية

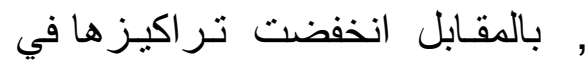

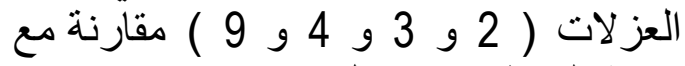
عينـة السيطرة ( جدول رقم / 2 ( 2 ) .

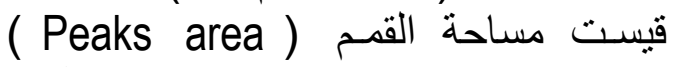
بطريقة الكر وماتوكر افي الغازية لكل

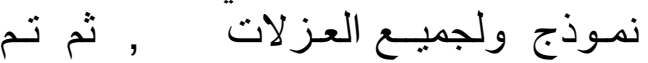

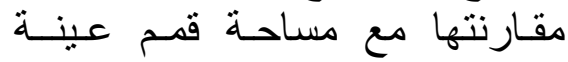

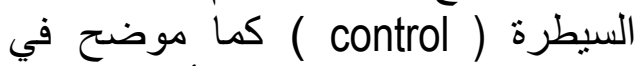

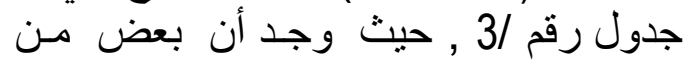

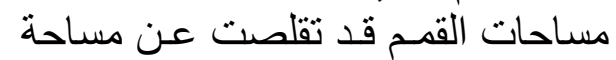
(القـم لنفس زمن الاحتباس مetention )

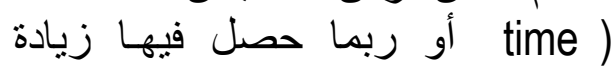

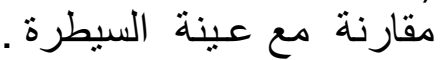

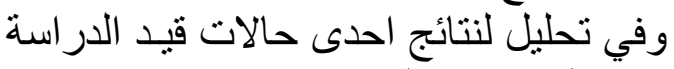

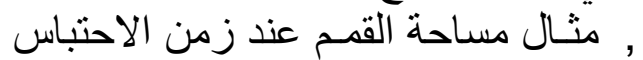

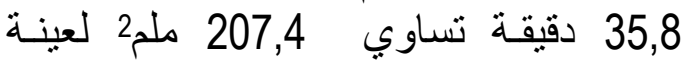

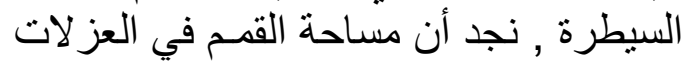

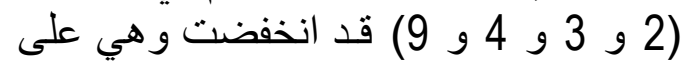
التوالي (صفر و صفر و 29.8 و صفر و ونف )

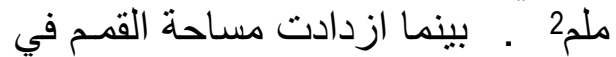
العزلات ( 1 و 5 و 6 و 7 و 8 و 8 و 10 ) ) و هي على التوالي ( 231.5, و و 240.1 و 264.1 و و و

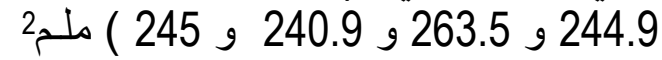
كمـا لوحظ اختفـاء بعض القهم كما هو حاصل في زمـن الاحتباس حيث وجد أن الاختفاء كان في نماذج الانياء العزلات ( 1 و 6 و 7 و 9 و ) .

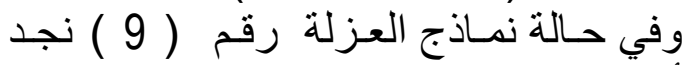

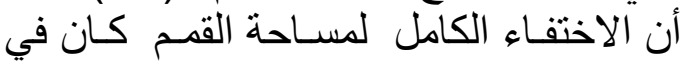
أزمان الاحتباس ( 32 و و 35,8 و 35 و 40,7 و 46,8 و 51,7 الاحتبان ) دقيقة .

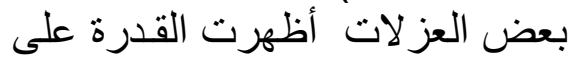

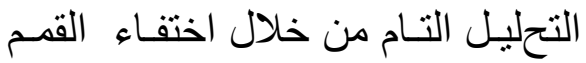

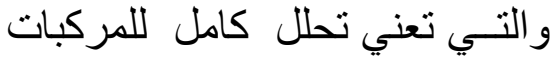
الهيدروكربونية الى مكوناتها الاولية ولي وهي لإنيات

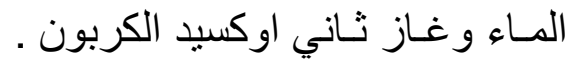

في حين أظهرت عزلات أخرى قابلية على الجى الخيل

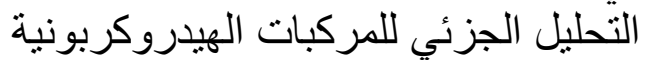

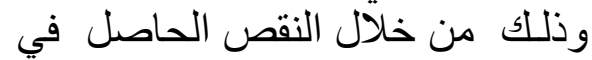

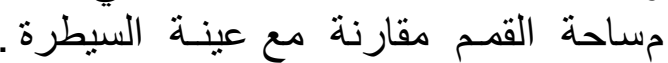

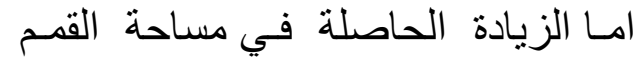

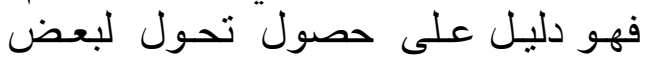
المركبات من شكل الى شكل فيل آخر موجود

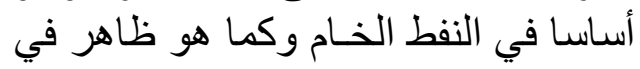

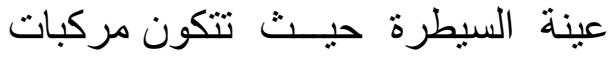

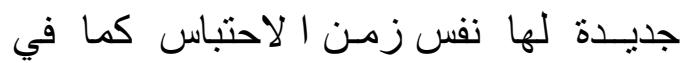

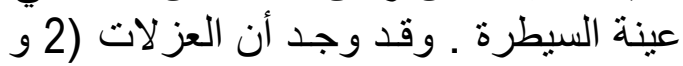

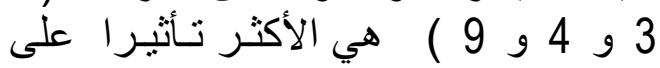
مكونات النفط الخـام . Larter et ) در اسات لباحثين آخرين مثنل al., 2006 , Das and Mukherjee, 2007 ; Adebusoye et al., 2007 ; Brooijmans ( et al., 2009 مجهرية مسن اجناس أخرى كانت

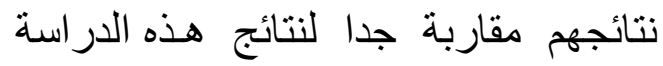

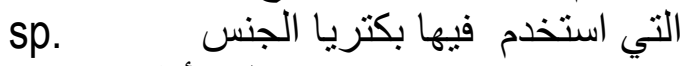
Streptomyces

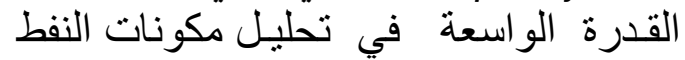

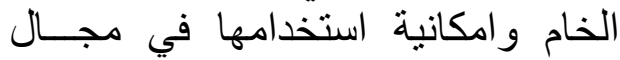
معالجة تلـوث البيئة بالنفط الخام الذي الذي

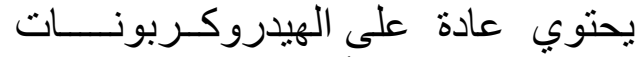

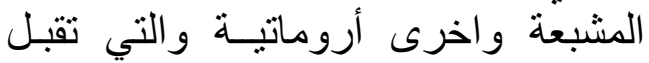

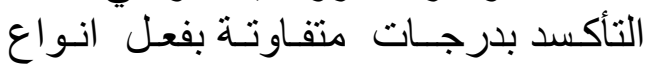

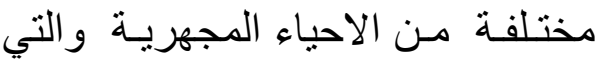

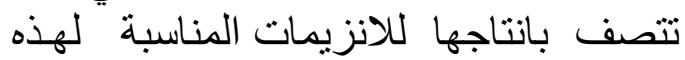

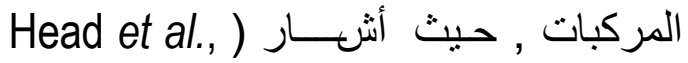

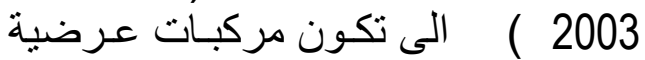

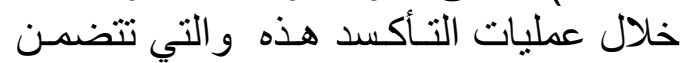

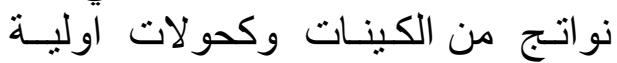

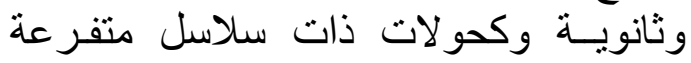

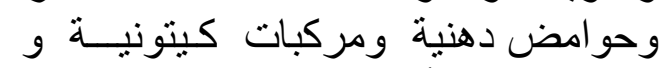
غير ها , وقد أكد (Larter et al. , 2005 ) وهنة على أن للاحياء المجهرية دور في زئد زيادة

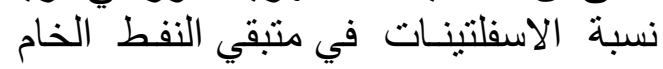

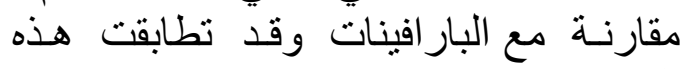

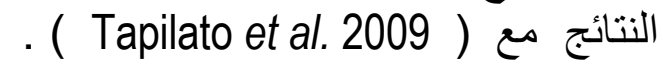




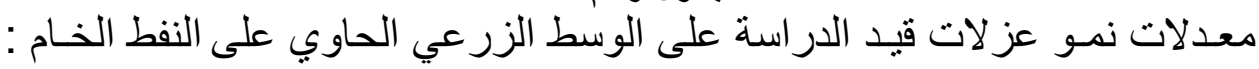

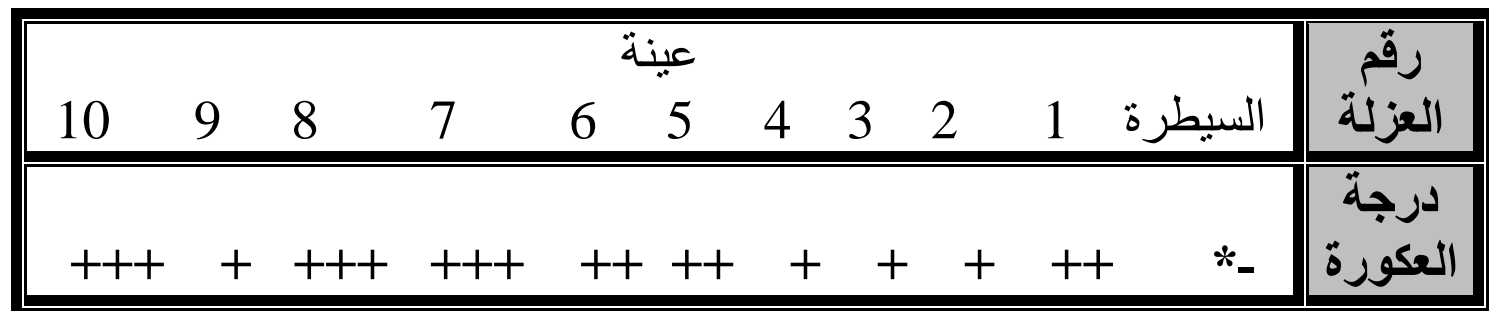

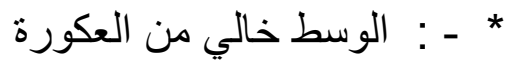

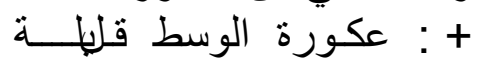

$$
\begin{aligned}
& \text { +++ : عكورة الوسط متوسطة } \\
& \text { ++++ عكورة الوسط عـاليــة }
\end{aligned}
$$

جدول رقم / 2

النسب المئوية للمركبات الهيدروكربونية المشبعة و الاروماتية المتبقية في الوسط

\begin{tabular}{|c|c|c|}
\hline \% للإيدروكريونات & \% للإيدوكربونات & رقم العزلــــة \\
\hline 26,5 & 73,5 & عينة السيطرة \\
\hline 29,5 & 70,5 & 1 \\
\hline 12,6 & 87,4 & 2 \\
\hline 17,3 & 82,7 & 3 \\
\hline 21 & 79 & 4 \\
\hline 31,4 & 68,6 & 5 \\
\hline 29,7 & 70,3 & 6 \\
\hline 38,5 & 61,5 & 7 \\
\hline 45,7 & 54,3 & 8 \\
\hline 23,8 & 76,2 & 9 \\
\hline 41,9 & 58,1 & 10 \\
\hline
\end{tabular}

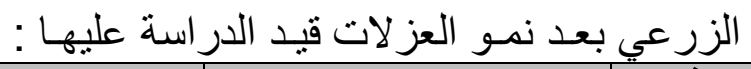




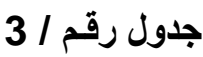

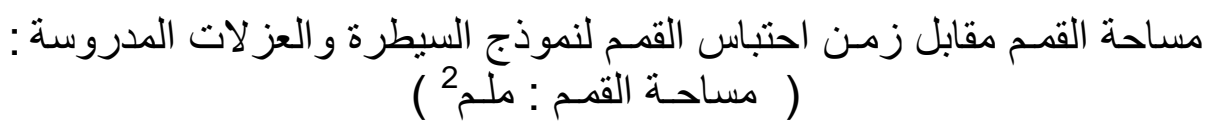

\begin{tabular}{|c|c|c|c|c|c|c|c|c|}
\hline 59,1 & 51,7 & 46,8 & 40,9 & 35,8 & 32 & 26,9 & 2,31 & الاحتباس \\
\hline 88,3 & 118,7 & 150 & 188,9 & 207,4 & 264,4 & 109,3 & 1423,5 & السيطرة عينة \\
\hline & & & & & & & & العز لات: \\
\hline 94,6 & 114 & - & 175,2 & 231,5 & 267,1 & 101,2 & 8857 & 1 \\
\hline 22 & 54,1 & 72,2 & 104,1 & - & 98,1 & 23,3 & 1234,5 & 2 \\
\hline 19,2 & - & 86,4 & - & - & 101,5 & 20,9 & 1244,3 & 3 \\
\hline - & - & 69,5 & - & 29,8 & 89,4 & 24,1 & 8523,1 & 4 \\
\hline 78,7 & 122,4 & 146,2 & 149,1 & 264,1 & 273,5 & 169,7 & 6565,1 & 5 \\
\hline 86,5 & 207,1 & - & 158,8 & 244,9 & 277,1 & 125,2 & 2319,2 & 6 \\
\hline 81,8 & 184,4 & - & 172,2 & 263,5 & 268,2 & 188,5 & 3511 & 7 \\
\hline 85,4 & 138,7 & 128,2 & 180,4 & 240,9 & 270,9 & 165,1 & 4210,1 & 8 \\
\hline 16,8 & - & - & - & - & - & 21,7 & 4798,2 & 9 \\
\hline 89,9 & 154,1 & 131,9 & 173,2 & 245 & 268,8 & 172,5 & 5771 & 10 \\
\hline
\end{tabular}




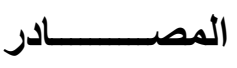

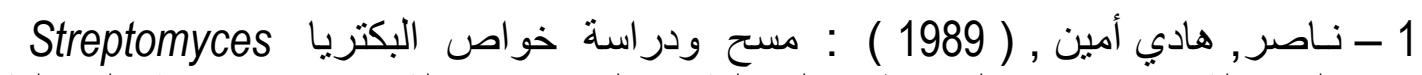

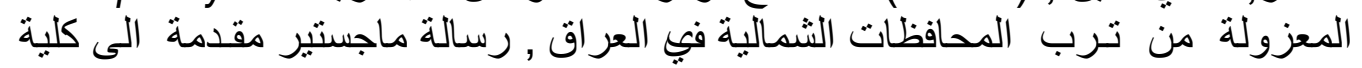
العلوم - جامعة صلاح الدين , ص. صن الصن 25 , 38 .

2- Adebusoye, S.A. ; M.O. Ilori ; O.O. Amund ; O.D. Teniola and S.O. Olatope ( 2007 ) : Microbial degradation of petroleum hydrocarbons in a polluted tropical stream, World J. of Microbiology and Biotechnology, vol. 23 , no. 8, p. $1149-59$.

3 -Al-Haidary,N.K., ( 1977) : Microbiol. Spoilage of Hydraulic and bearing oils, $\mathrm{Ph} . \mathrm{D}$. thesis, univ. college Cardiff .

4- Baron,E.J. and S.M. Finegold, ( 1994) : Microorganisms encountered in U.T.I. in Baily \& Scotts Diagnostic microbiology, $9^{\text {th }}$ ed. Mosby com. U.S.A.

5- Brooijmans, R.J.W.; M.I. Pastink and R.J. Siezen ( 2009 ) : Hydrocarbon- degrading bacteria: the oil spill clean up crew, J. Microbial. Biotechnology, vol. 2 , no. 6 , p. $587-94$.

6- Chaillan, F. ; A. Le Fleche ; E. Bury ; Y. H. Phantavong ; P. Grimont; A.Saliot and J.Oudot (2004): Identification and biodegradation potential of tropical aerobic hydrocarbon - degrading microorganisms , J. Research in Microbiology , vol. 155 no. 7 , p. $587-95$.

7- Das, K. and A. K. Mukherjee ( 2007 ) : Crude petroleum-oil Biodegradation efficiency of Bacillus subtilis and Pseudomonas aeruginosa strains isolated from a petroleum- oil contaminated soil from North-East India, J. Bioresource Technology, vol. 98 , no. 7 , p. $1339-45$.

- Head, I. M. ; D. M. Jones and S. R.Larter (2003): Biological activity8 in the deep subsurface and the origin of heavy oil, J. Nature vol. 426 , p. $344-52$.

9- Larter, S. R. ; A. Wilhelms ; I. Head ; M. Koopmans ; A. Aplin ; R. Di Primio ; C. Zwach ; M. Erdmann and N. Telnaes (2003): 
The controls on the composition of biodegraded oils in the deep subsurface, Part I : Biodegradation rates in petroleum reservoirs, J. organic chemistry, vol. 34 , p. $601-13$.

10- Larter, S.R. ; I.M. Head ; H. Huang ; B. Bennett ; M. Jones ; A.C. Aplin ; A.Murray; M. Erdmann; A.Wilhelms and R. Di Primio (2005): Biodegradation, gas destruction and methan generation in deep subsurface petroleum reservoirs, Proceeding of the $6^{\text {th }}$ Petroleum Geology Conference, Geological Society (London), p. $633-40$.

11- Larter,S.R.; H.Huang; J. Adams; B. Bennett;O. Jokanola ; T.Oldenburg ; M. Jones ; I. Head ; C. Riediger and M. Fowler ( 2006 ) :The controls on the composition of biodegraded oils on the deep subsurface ,Part II: Geological controls on the subsurface biodegradation fluxes and constraints on reservoir - fluid property prediction : AAPG Bulletin, vol. 90 , p. $921-38$.

12- Pridham, T.G. and D. Gottlieb, ( 1948 ) : The utilization of some carbon compounds by some Actinomycetales as an aid for species determination, J. of Bacteriol. 56: pp. $107-114$.

13 - Tapilatu , Y.; M. Acquaviva ; C. Guigue ; G. Miralles ; J. C. Bertrand

degrading bacteria and P. Cuny ( 2009 ) : Isolation of alkane - rom deep- sea Mediterranean sediments, Appl. Microbiology, $\mathrm{f}$ vol. $50: 2$, pp. $234-36$.

14- Wilhelms , A. ; S.R. Larter ; I. Head ; P. Farrimond ; R. Di Primi and C. Zwach ( 2001 ) : Biodegradation of oil in uplifted basins prevented by deep-burial sterilization, J. Nature, vol. 411 , p. $1034-37$. 


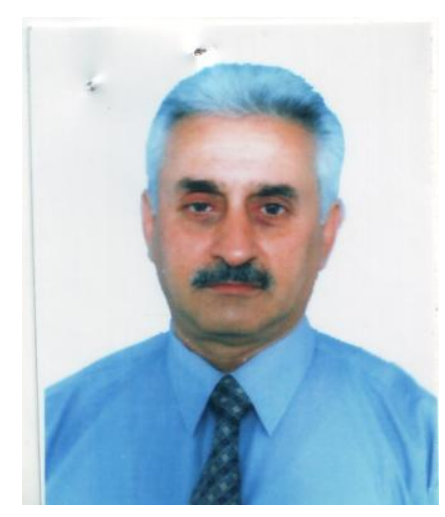

الاسم : نزار أدور ناصر جرجيس الصائغ العنوان الوظيفي : استاذ مساعد المواليد :1950 بصرة /العراق

موقع العمل :كلية العلوم / الجامعة المستنصرية التحصيل الدراسي: دكتوراه فلسفة في علوم الحياة (احياء مجهرية) جامعة كوزا /مدينة ياش _ رومانيا 